\title{
Environmental Analysis on Rural house with Circulated Energy Utilizations in Northern China
}

\author{
Xueyan Zhanga, Bin Chen \\ Laboratory of Building Environment and New Energy Resources, School of Civil Engineering, Dalian \\ University of Technology, Dalian, Liaoning 116024, China \\ axueyan@dlut.edu.cn
}

\begin{abstract}
Keywords: Circulated energy utilizations; Burning cave; Air quality; Thermal environment; Rural house
\end{abstract}

Abstract. The rural house with comprehensive circulated utilization systems has been designed and built in a village around Fuxin city, which could separate production from living region. At the same time the energy circulation could be taken out. This new design mode could solve the following actual problems in Northern China, such as single energy utilization mode with lower thermal efficiency, poor thermal comfort in a house, serious heat loss and lower temperature in traditional greenhouse at night. During heating in winter, air quality, soil temperature, surface temperature on the burning cave, indoor and outdoor air temperature and relative humidity have been measured. The results show that the indoor air temperature is increased by $3 \sim 5^{\circ} \mathrm{C}$ and temperature fluctuation is inhibited in a room heated by burning cave. The revenue of planting and breeding industry can be effectively increased by 20 percent. The biogas can be continuously generated while using a burning cave to provide heat for the methane tank. This mode can save 35 percent of the total energy consumption for production and household daily lives in winter. Therefore, the circulated energy utilization systems based on biomass and solar energy use integrated in rural house could show remarkable effects and great technological progress.

\section{Introduction}

For thousands of years, traditional heating methods in rural areas of northern China have always been used, such as different kangs, hot wall heated by high temperature smoke, burning cave and other heating systems. They are effective approaches for inhabitants living in the long cold winter. Greenhouse is very important for agricultural production in China. However, the temperature for vegetables growing could not meet the requirements while the amount of insolation absorbed only through the roof of greenhouse covered with transparent materials all day long time in winter China. Especially, vegetables in the night would stop growing for a long time, even in danger of damaged or freezing to death. The phenomenon of lower thermal efficiency, lower economic benefits, and the mode of unidirectional energy utilization in a traditional greenhouse are very common [1]. In order to solve the above problems, the burning cave with direct combustion of fuels, pipe heating system with hot water, solar heating with phase change materials, radiators and electric heating systems have been used by some local craftsmen. These heating systems could only improve partial indoor air temperature. However, uneven heat distribution, lower temperature of the soil, intermittent heating, high cost on commercial energy consumption, and high carbon emissions are still exist [2]. Therefore, planting vegetables and breeding livestock could be hardly operated, resulting in a lower productivity and lower economic returns directly impact on the quality of rural residents' daily lives.

Some significant theory analysis and experimental studies have been carried out. In the early 20th century [3], the systematic study of greenhouses have been taken by abroad academics. In Japan, America, France and other countries, heating system with soil storage in greenhouse have already been widely studied [4][5]. In 1979, a new solar plastic greenhouse with a thermal storage system underground has been completed by Japanese scholars Yujiro Yamamoto, the indoor air temperature during the night could be increased by $1{ }^{\circ} \mathrm{C} \sim 3^{\circ} \mathrm{C}$ [6]. In 1980, heat storage water tank placed inside the greenhouse has been developed by Baxter. DO, and through heat release process to heating the 
whole greenhouse in Japan. At the same time, taking heat exchanging system underground to heat a greenhouse or a livestock shed have been widely applied in the United States, France and other countries [7]. In China, since the early 1980s, some scholars began to do some experimental studies on the heating effect of the heat exchanging devices underground in the greenhouse [8]. Tieliang Wang et al. [9] have studied on the fire-pit and underground heat exchanging system for a greenhouse heating, and the results show that the air temperature and soil temperature have been significantly improved in a large type greenhouse. In addition, related literature research shows that the heat transfer through the soil directly is a better approach, and the temperature in the soil at the distence of 7 meters from the center of the fire-pit could be increased by $1.76^{\circ} \mathrm{C} \mathrm{[10].}$

In this paper, a circulating ecological courtyard based on the renewable energy utilization has been designed and constructed. Especially, thermal performance and economic benefits of the optimized integrated greenhouse with a burning cave and a biogas digester have been mainly researched.

\section{Design Mode}

Integrated Design. In order to achieve the purpose of energy cycling utilization and maximum economic benefits, and separate agricultural production from daily living areas, a circulating ecological courtyard including optimized greenhouse and solar house has been designed and built in a village of rural Fuxin, Liaoning Province. Its practical engineering and structural diagram are shown in Fig. 1 (a), (b), and (c), the household courtyard was constructed by a passive solar house integrated with a burning cave (using renewable energy), and an optimized two-story greenhouse, including livestock house, bathroom, biogas digester, kitchen, and burning cave. In this paper, the innovative two-story greenhouse is the study object. The height of each floor is about $2 \mathrm{~m}$, and the length is $12 \mathrm{~m}$ (from the east to the west). The span of the first floor is $3.5 \mathrm{~m}$ (from the north to the south, for vegetables planting), and the second floor is $6.5 \mathrm{~m}$ (including $3.5 \mathrm{~m}$ is for vegetables planting, and $3.0 \mathrm{~m}$ is for livestock breeding.). The burning cave with a diameter of $2 \mathrm{~m}$, a height of $1.5 \mathrm{~m}$, placed under the poultry house (The center of the burning cave is $3 \mathrm{~m}$ away from the north wall, and 5m away from the east wall.). The rounded methane tank with a diameter of $1.5 \mathrm{~m}$, also placed under the second floor. The center distance between the above two pits is about $2.5 \mathrm{~m}$.
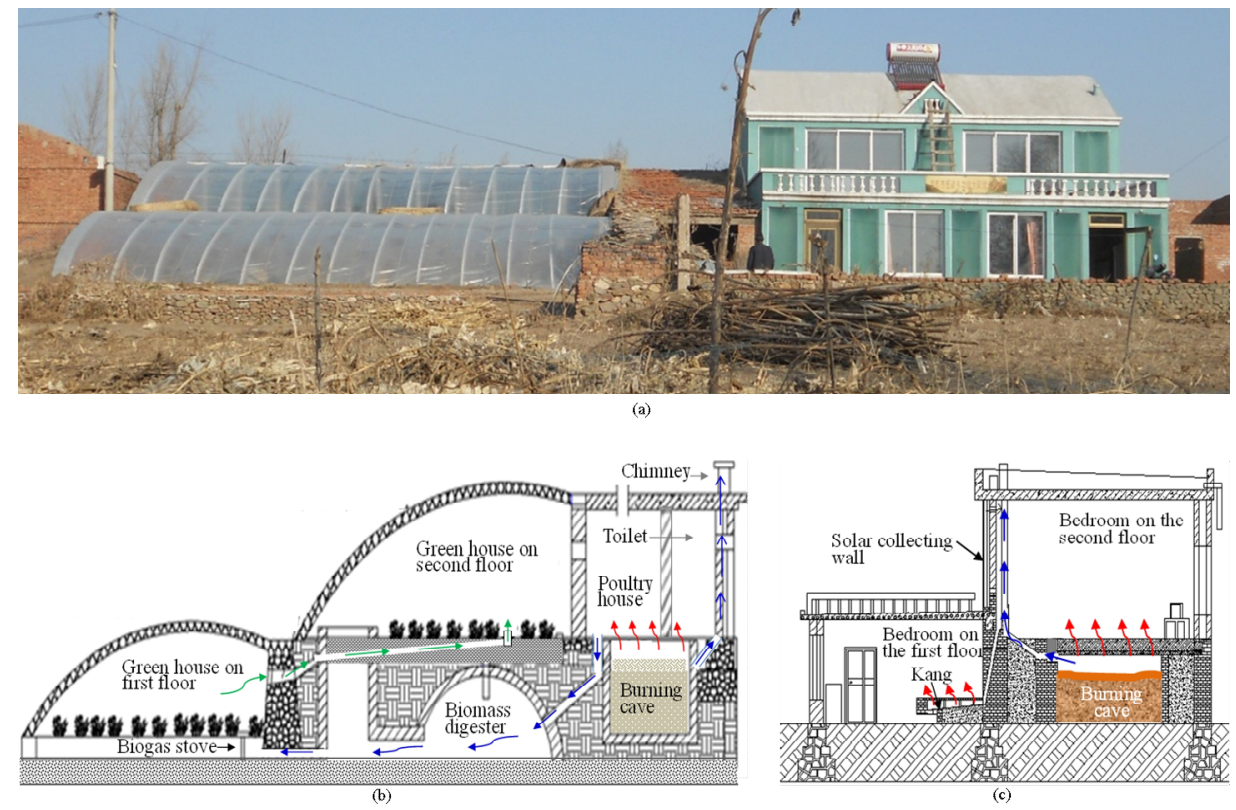

Fig.1, The structure of ecological courtyard and sketch of energy utilization systems ((a) A picture of the ecological courtyard; (b) Vertical profile of the optimized two-story greenhouse; (c) Vertical profile of the dwelling with renewable energy utilization systems 
Energy Recycling Utilization. The diagram of the energy cycling mode is shown in Fig. 2. Burning cave, the key point in the greenhouse, is used for heating the indoor environment and warming the biogas digester by once filling in the whole heating period (from January in 2010 to February in 2010). One the one hand, inside the burning cave, the heat generated from smoldering biomass fuels can be used for warming the livestock shed through the radiant heating ground and keeping an appropriate temperature for vegetables through the soil. Besides, the biogas slurry and residues can be used as fertilizer for vegetables and fruits. On the other hand, as burning cave is used for heating the room shown in Fig.2, the indoor thermal environment and air quality can be improved. Furthermore, the energy consumption of the whole house can be saved more.

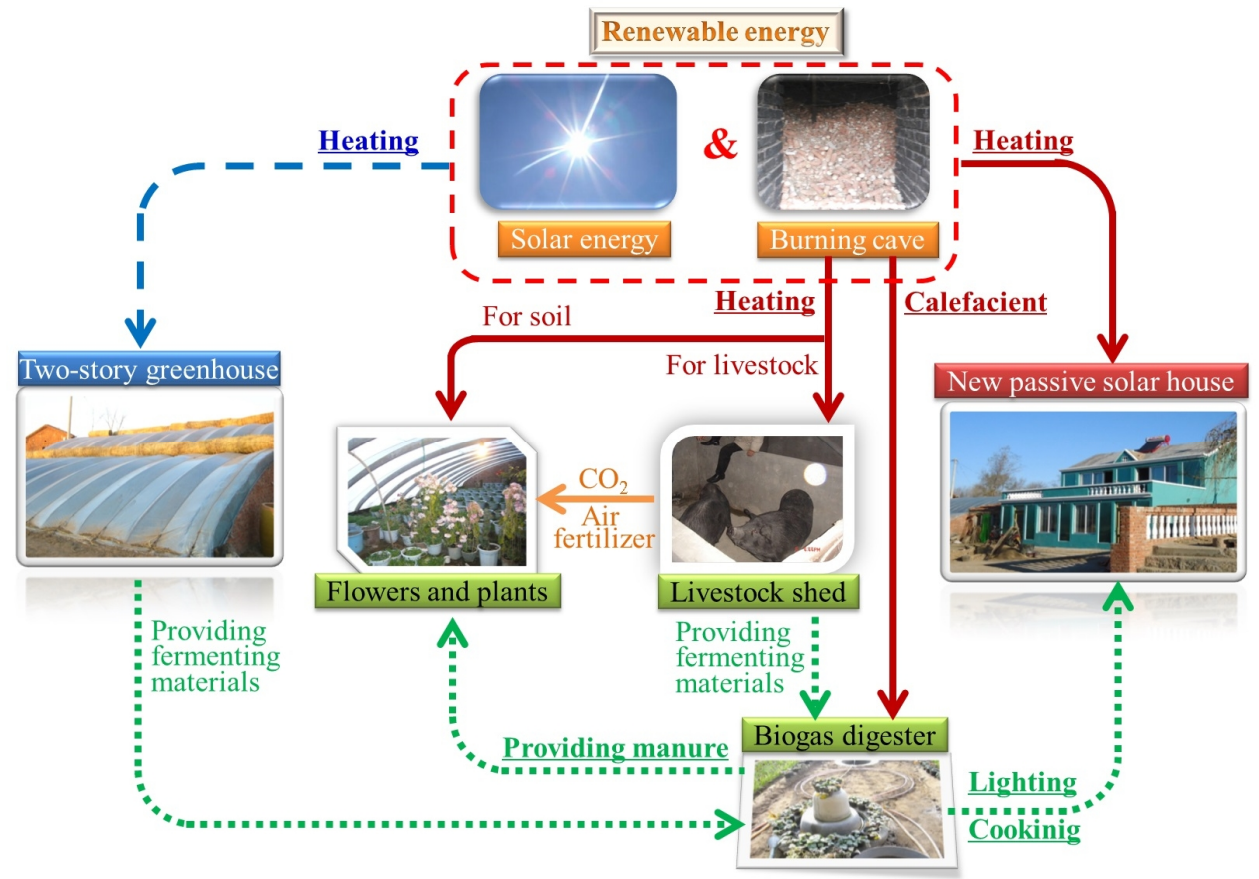

Fig.2, The schematic of an ecological cycling mode

\section{Testing Conditions and Measurements}

During the measurement process, taking straw debris as fuels in the burning cave, and the quality was $522 \mathrm{~kg}$. In addition, the quality of the water added to the fuels was about $130 \mathrm{~kg}$. By calculation, the water content of the mixed fuels is about $25 \%$, and the calorific value is $7500 \mathrm{~kJ} / \mathrm{kg}$. Finally, the dry straw debris, put on the top of the mixed fuels for igniting, was about $90 \mathrm{~kg}$. From January 2010 to January 2011, Chinese chives and small tomatoes have been planted, and the black pigs have been bred in the livestock shed in the greenhouse.

In order to study the heating effects of the burning cave and the economic benefits of the optimized two-story greenhouse, a number of measurements have been taken. At the same time, the same measurements have been done in a contrastive greenhouse heated by radiators. The materials of the around walls in the above two greenhouses are the same and shown in Fig.3. The test points and measurement process in the two greenhouses are illustrated respectively in Fig. 3. Such as, the indoor/outdoor temperature and relative humidity were measured by thermo recorder TR-72U, which was arranged on a height of 1.1 to $1.5 \mathrm{~m}$ above the soil surface. The $\mathrm{CO}, \mathrm{C}_{\mathrm{O} 2}$ concentrations in the center of the greenhouse and on the outlet of the chimney were separately measured by an indoor air quality meter TSI7545 and gas analyzer Testo 340. The heat transfer process is from the burning cave to the soil has been measured by data logger SWP-L816. The surface temperatures on the ground and the soil were tested by infrared camera FLIR B250. Temperatures inside the burning cave were 
measured by circuit monitoring system with high temperature test-points connected to the computer recorded by 10 minutes.

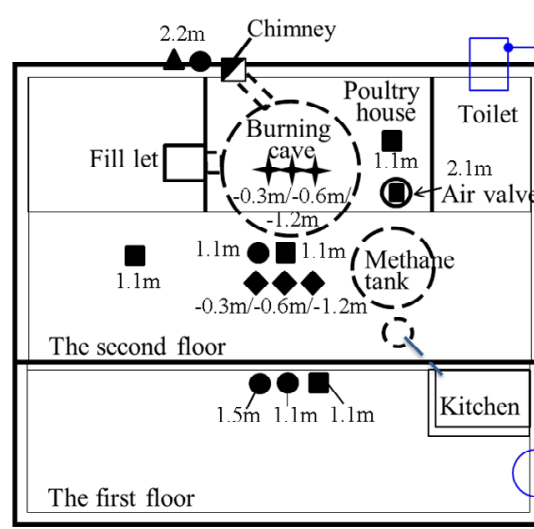

(a)

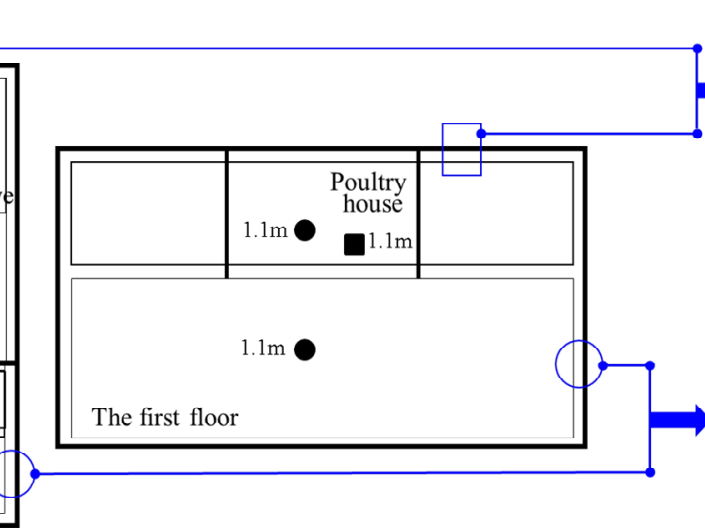

(b)
$\mathrm{K}_{1}=0.72 \mathrm{~W} /\left(\mathrm{m}^{2} \cdot \mathrm{K}\right)$
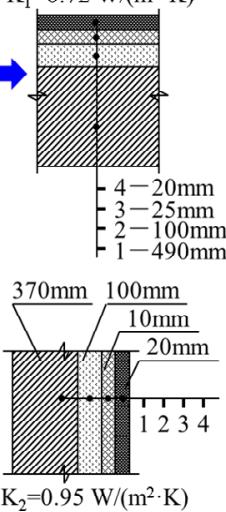

(c)

$\Delta$ Pollutants tests Temp and RH tests $\square \mathrm{CO} / \mathrm{CO}_{2}$ Test points 1. Brick 2. Concrete 3. Polystyrene board 4. Cement mortar

+ Temperature tests inside the burning cave Temperature tests in the soil

Fig.3, Test points arrangements ((a) Optimized two-story greenhouse; (b) Conventional greenhouse; (c) materials of the walls)

\section{Results Analysis}

Temperature Variation in the Burning Cave. As shown in Fig.4, the temperature of the combustion fuels is increased from $10^{\circ} \mathrm{C}$ to $430^{\circ} \mathrm{C}$ in the process of combustion. Based on the three peak values in Fig.4, the average burning velocity of the fuels is about $2.6 \mathrm{~mm} / \mathrm{h}$ through calculation. The temperature of the smoke inside the burning cave is decreased from $160^{\circ} \mathrm{C}$ to $15^{\circ} \mathrm{C}$. In addition, temperature of the inside surface below the cover plate on the top of the burning cave is decreased from $113^{\circ} \mathrm{C}$ to $18^{\circ} \mathrm{C}$. The main reason is that as the height of the fuels was reduced, the space between the burning surface and the cover plate could be larger, and the cold air infiltration could be increased.

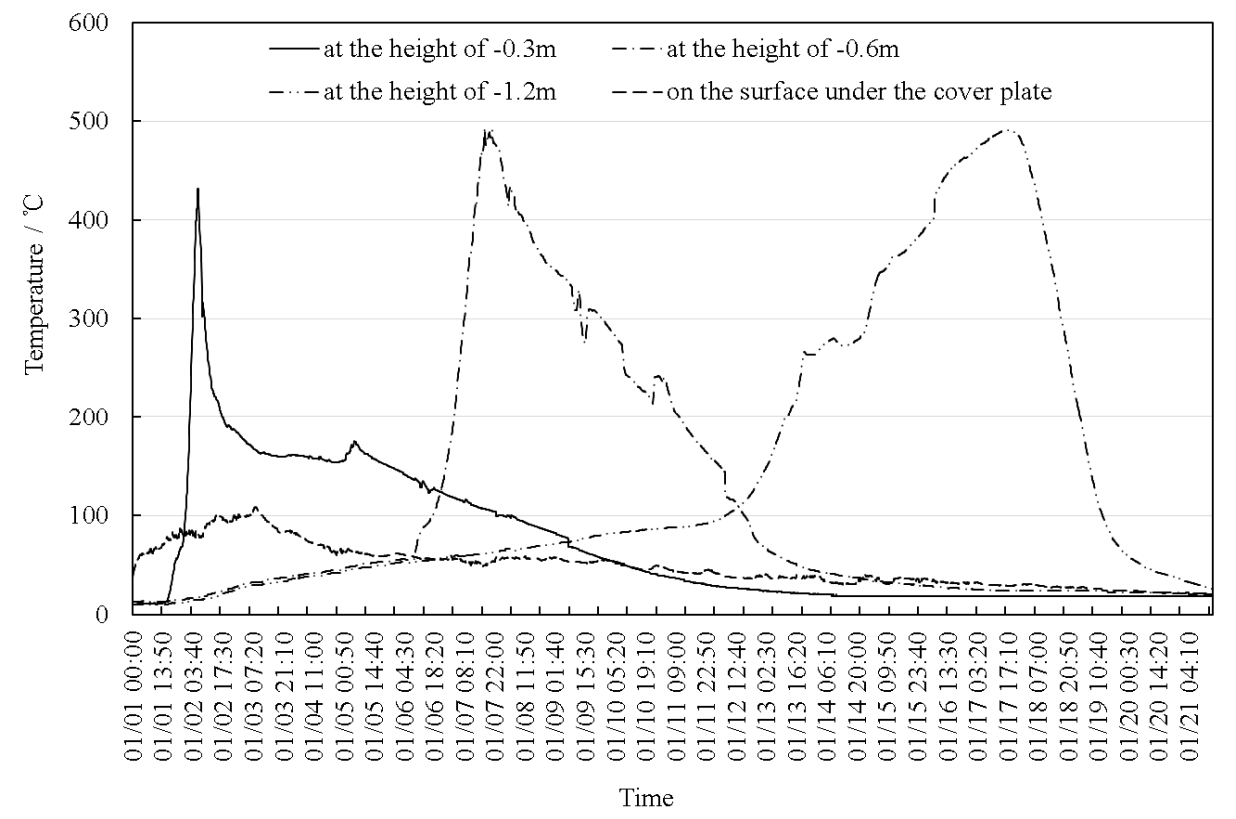

Fig.4, Temperature variation of different test points inside the burning cave

Heat Transfer through Soil. It is assumed that the component of the soil was clay and its coefficient of heat conductivity was between $0.85 \mathrm{~W} /\left(\mathrm{m}^{2} \cdot \mathrm{K}\right)$ and $1.1 \mathrm{~W} /\left(\mathrm{m}^{2} \cdot \mathrm{K}\right)$. The heat transfer through the soil could be discussed as the heat transfer through the semi-infinite object. Based on the 
results shown in Fig. 5(a), taking into consideration of the temperature variation in the soil and ignoring the process of moisture transfer and the latent heat of vaporization, the heat flux inside the soil have been calculated through the formula from reference. As shown in Fig.5(b), the largest values of heat flux are respectively $510 \mathrm{~W} / \mathrm{m}^{2} 、 405 \mathrm{~W} / \mathrm{m}^{2} 、 500 \mathrm{~W} / \mathrm{m}^{2}$ (1m away from the burning cave). While the original temperature inside the soil was $7^{\circ} \mathrm{C}$, the highest temperature inside the biogas digester could be up to $32.3^{\circ} \mathrm{C}$, and the lowest temperature could be $18^{\circ} \mathrm{C}$, which is available for producing biogas normally. Therefore, a biogas digester could be constructed in the place at a distance of $1 \mathrm{~m} \sim 1.5 \mathrm{~m}$ far away from the burning cave.

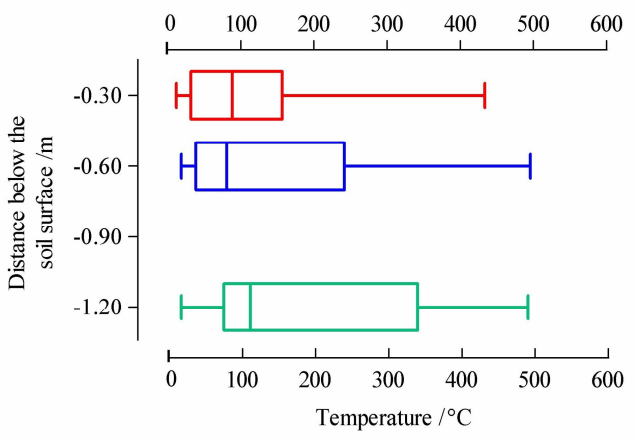

(a)

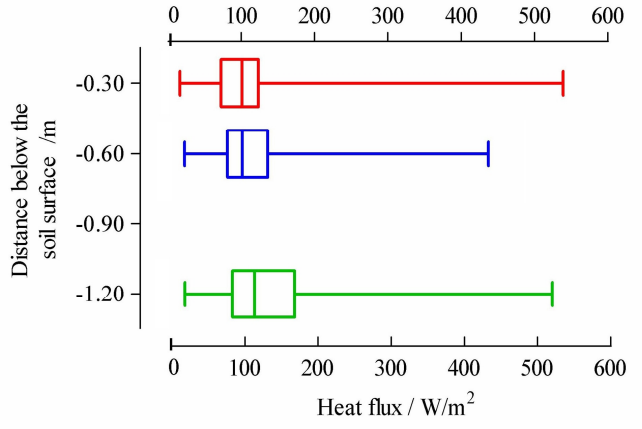

(b)

Fig.5, The heat flux variation in different depth of the soil ((a) The smoldering temperature inside the burning cave; (b) The soil heat flux)

Indoor Air Temperature. As can be seen in Fig.6, when the average outdoor air temperature is lower than $-20^{\circ} \mathrm{C}$, the indoor air temperature of the optimized house is $3^{\circ} \mathrm{C} \sim 5^{\circ} \mathrm{C}$ higher than which in traditional house. It illustrated that burning cave has done a better heating effect than radiator heating system. It demonstrates that burning cave heating could effectively inhibit the temperature fluctuations inside the house, and inside the greenhouse burning cave can be provide a suitable temperature for vegetables growing. In addition, the photosynthesis and productivity of vegetables can be twice than before, while the air temperature increased by $10^{\circ} \mathrm{C}$. By comparing analysis between indoor and outdoor air temperature in Fig.7, the correlation between the above two parts is exponential function relation inside the optimized two-story greenhouse, but logarithmic function relation is in the traditional greenhouse.

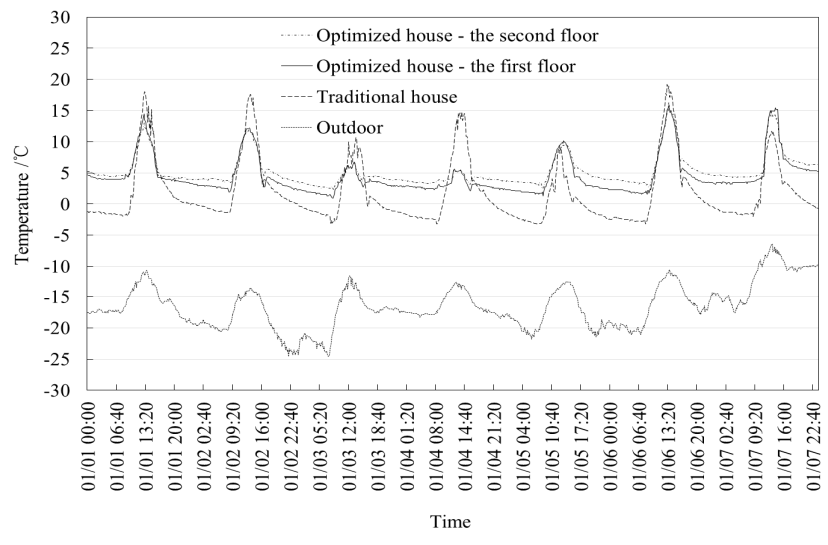

Fig.6, Indoor and outdoor air temperatures

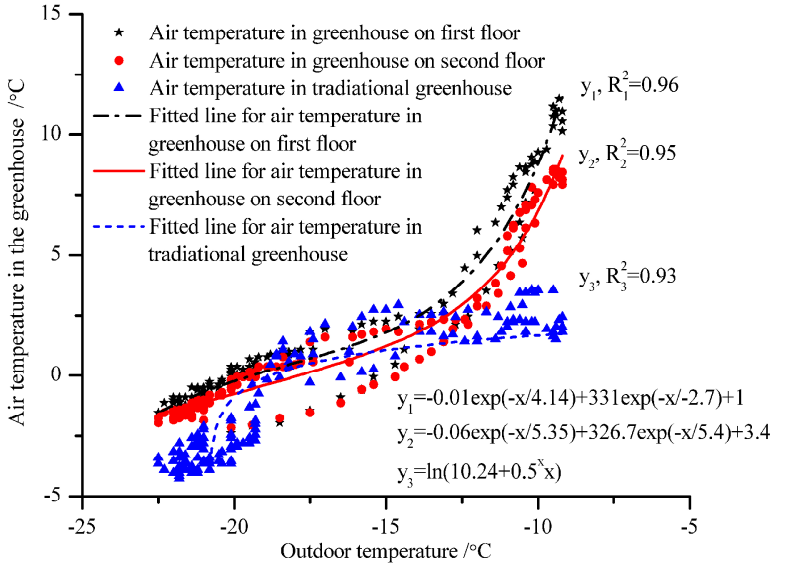

Fig.7, The relationship of air temperature

Air Quality. As shown in Fig. 8, $\mathrm{CO}$ concentration and $\mathrm{CO}_{2}$ concentration of the optimized house is lower than the limits of Chinese indoor air quality standard at the most of time. In addition, $\mathrm{CO}_{2}$ concentration is $1700 \mathrm{mg} / \mathrm{m}^{3}$. As the $\mathrm{CO}_{2}$ concentration increased twice, the carbon absorption rate for photosynthesis can be increased by $21 \%-26 \%$. Most of time-averaged values of $\mathrm{CO}$ and $\mathrm{CO}_{2}$ concentrations are lower than the limits of Chinese standard [11]. However, in optimized greenhouse, 
$\mathrm{NO}$ and $\mathrm{NO}_{2}$ concentration on the exhausting outlet of the animal house is about $3 \mathrm{ppm}$, which is lower than the limit (5ppm [11]) bad for plants growth. Taking the production area and living area as independent parts can prevent the contaminants from entering into the eco-house. While the larger wind speed in winter is helpful for the diffusion of contaminants.

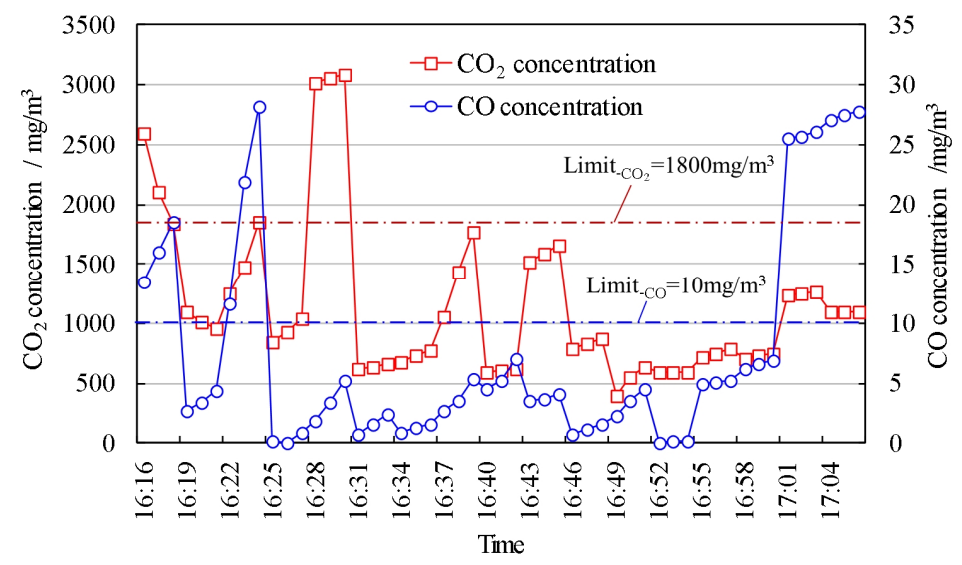

Fig.8, The variation of $\mathrm{CO}$ concentration and $\mathrm{CO}_{2}$ concentration of the optimized house

\section{Life Cycle Cost Assessment}

Economic analysis is important as discussed above. Some details have been discussed in reference [12]. The life cycle cost (LCC) assessment has been used to analysis some costs during the four stages, such as decision, design, construction, operation and maintenance. The LCC between the optimized greenhouse integrated with a burning cave and the conventional greenhouse designed by craftsmen was calculated based on the equations in reference [12]. The assumption conditions including that the design life cycle was 50 years, and the discount rate was 0.6. The results are shown in Fig.9. Design and construction stage impacting on the whole LCC may be as high as $90 \%$. In operation and maintenance stage, it may accounts for about $25 \%$. Fig. 9 also shows that the potential cost saving of the optimized greenhouse with a burning cave is about 150 Yuan per square meter. Finally, the LCC of the integrated greenhouse could be controlled to be less than 115 Yuan per square meter, which is an affordable price for rural residents.

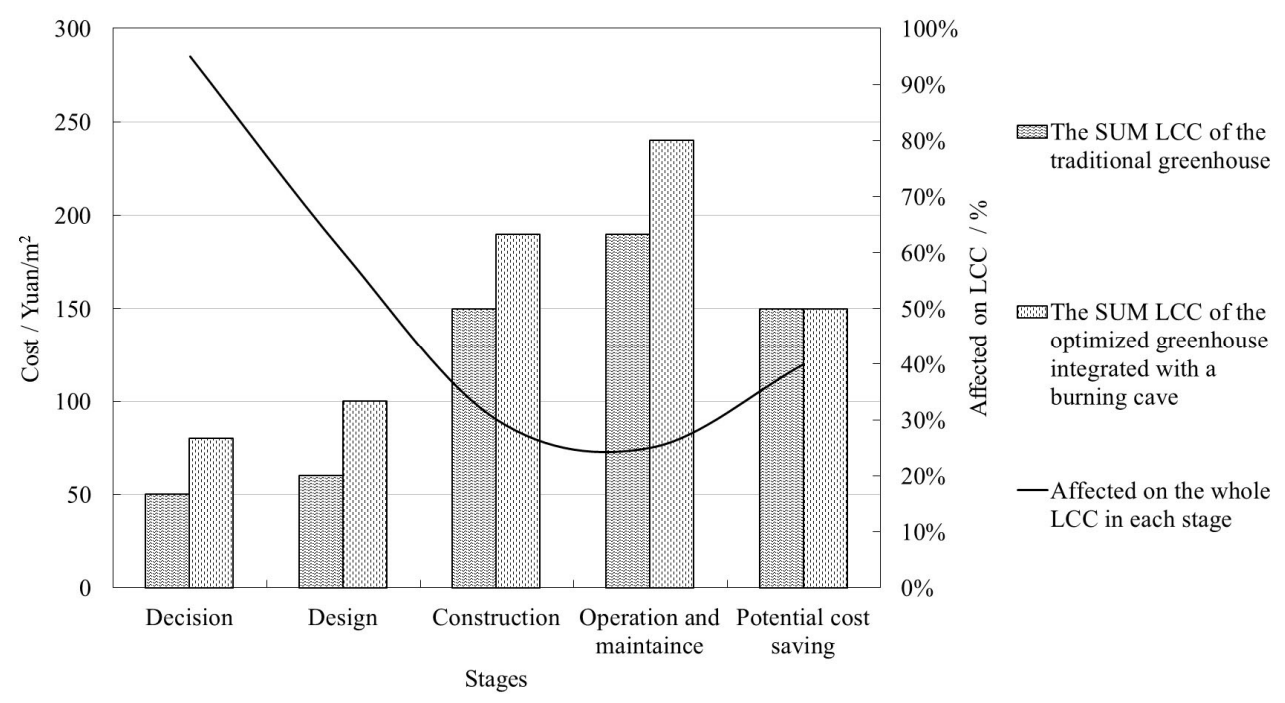

Fig.9, The influence on the whole life cycle cost 


\section{Conclusions}

By comparing analysis between optimized house with ecology greenhouse and traditional houses, the main conclusions are summarized as follows:

(1) While using a burning cave in the optimized house, the indoor air temperature was increased by $1.5^{\circ} \mathrm{C} \sim 3^{\circ} \mathrm{C}$, and the temperature difference between day and night was reduced to $6.5^{\circ} \mathrm{C}$. Besides, in the optimized greenhouse, average temperature of the surface on the heating ground in the livestock shed was up to $17^{\circ} \mathrm{C}$. It illustrates that the appropriate temperature is the basis of planting and feeding advanced species. Therefore, the economic benefit was effectively increased by 20 percent.

(2) The biogas was generated normally from the digester integrated in the greenhouse, warming by the burning cave, could save $30 \%$ of cooking and electricity energy consumption.

(3) The potential cost savings of the optimized greenhouse integrated with a burning cave could be about 150 Yuan per square meter, and the LCC could be controlled to be less than 115 Yuan per square meter, at the affordable price for rural residents.

\section{Acknowledgements}

The work was supported by a NSFC (No. 51608092) and the Fundamental Research Funds for the Central Universities (No. DUT16RC(3)092) of China. The authors are particularly grateful to Xingshan Liu, a craftsman from Fu Xin Countryside, for his cooperation and to other owners of all tested residences for their supports during experimental period.

\section{References}

[1] X.J. Yu. "Research on the active solar heating system of greenhouse in intense cold area." The Master Degree in Engineering of Northeast Petroleum University. 2011.3. (in Chinese)

[2] F.Q. Wang. "Application study on solar energy collecter for increasing soil temperature in solar greenhouse." The master dissertation of China Agricultural University. 2004.6. (in Chinese)

[3] Y.Q. Wang. "The development situation of greenhouses and agricultures in european union countries.” Henan Science \& Technology, 2000,9: 11-12. (in Chinese)

[4] K. Kwata, T. Takakura. "Underground storage of solar energy for greenhouse heating." Trans of the ASAE, 1991, 34(5): 2181-2186.

[5] P.D. Lund. "A numerical model for seasonal storage of solar heat in the ground by vertical pipes." Solar Energy, 1980, 34(4): 351-366.

[6] S. Yamamoto. "Solar green-house." Facilities for Horticulture, 1983, 30(5): 41-47.

[7] D.O. Baxter. "Energy exchanger and related temperatures of an earth--tube heat exchanger in the heating mode." Transactions of the ASAE, 1992, 35(1): 275-285.

[8] C.W. Ma. "Studies on the vinyl-house heating by the underground heat exchange system." Chinese Society of Agricultural Engineering (CSAE), 1985. 3(1): 54-65. (in Chinese)

[9] T.L. Wang, Y.K. Bai, W.H. Liu. "Experimental research on using fire pit to increase temperature in solar greenhouse." Transaction of the CSAE, 2002, 18(4): 98-100. (in Chinese)

[10] Y.K. Bai. "A study on the fire-pit and underground heating exchange system of solar greenhouse." A graduation thesis for a doctor degree of Shenyang Agricultural University. 2007.

[11] Department of health. "Indoor air quality standard" (GB/T18883-2002). China Architecture \& Building Press. 2002.

[12] J. Kneifel. "Life-cycle carbon and cost analysis of energy efficiency measures in new commercial buildings." Energy and Buildings, 2010, 42(2): 333-340. 